\title{
Correction to: Epigenetic regulation of neuronal immediate early genes is associated with decline in their expression and memory consolidation in scopolamine-induced amnesic mice
}

Sweta Srivas $^{1} \cdot$ Mahendra K. Thakur ${ }^{1}$

Published online: 24 July 2019

(C) Springer Science+Business Media, LLC, part of Springer Nature 2019

\section{Correction to: Mol Neurobiol (2017) 54:5107-5119} https://doi.org/10.1007/s12035-016-0047-4

The original article inadvertently had a mistake in Fig. 3a, b. The authors regret to these errors. Now the correct images are hereby published.

These corrections do not affect the content and conclusion of the manuscript. The authors apologize for any inconvenience caused to readers.
Fig. 3 Expression of neuronal immediate early genes decreases in hippocampal subregions during scopolamine (SC)-induced amnesia. a In situ hybridization analysis of Arc, Egr1, Homer1, and Narp mRNA expression showing photomicrographs of $\times 400$ magnification. b Immunofluorescence analysis of Arc, Egr1, Homer1, and Narp protein expression showing photomicrographs of $\times 400$ magnification. Histogram represents IDV/area after deduction of negative control and background values of corresponding hippocampal subregions from three independent experiments (mean \pm SEM). $* p<0.05$ denotes significant differences as compared to SA (independent-samples $t$ test). $D G$ dentate gyrus, $C A 3$ cornu ammonis 3, CAl cornu ammonis 1

The online version of the original article can be found at https://doi.org/ 10.1007/s12035-016-0047-4

Mahendra K. Thakur

mkt_bhu@yahoo.com

1 Biochemistry and Molecular Biology Laboratory, Brain Research Centre, Department of Zoology, Institute of Science, Banaras Hindu University, Varanasi 221005 , India 
a

Arc

DG

CA3

CAl

Negative
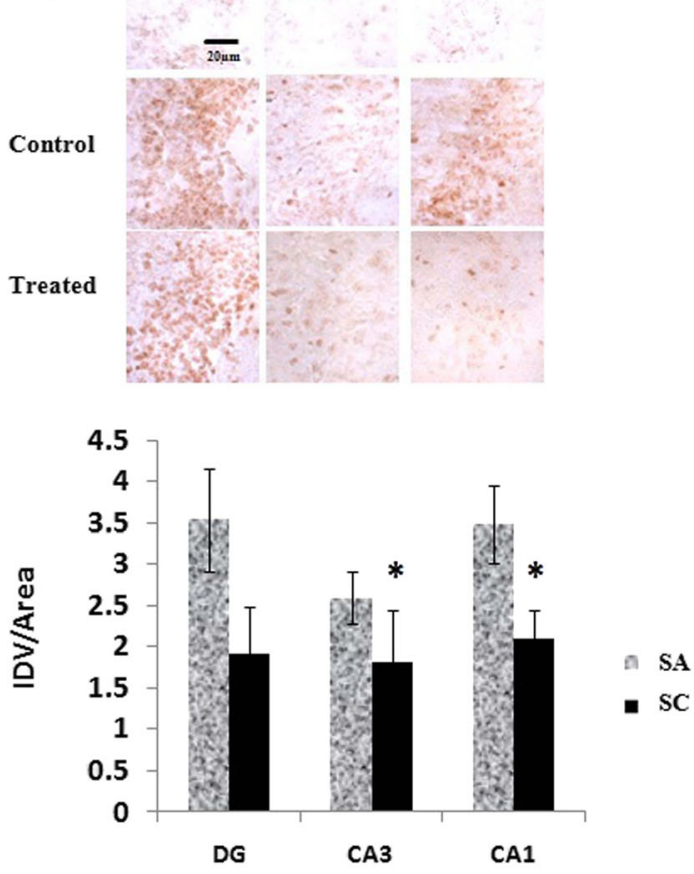

Homer1
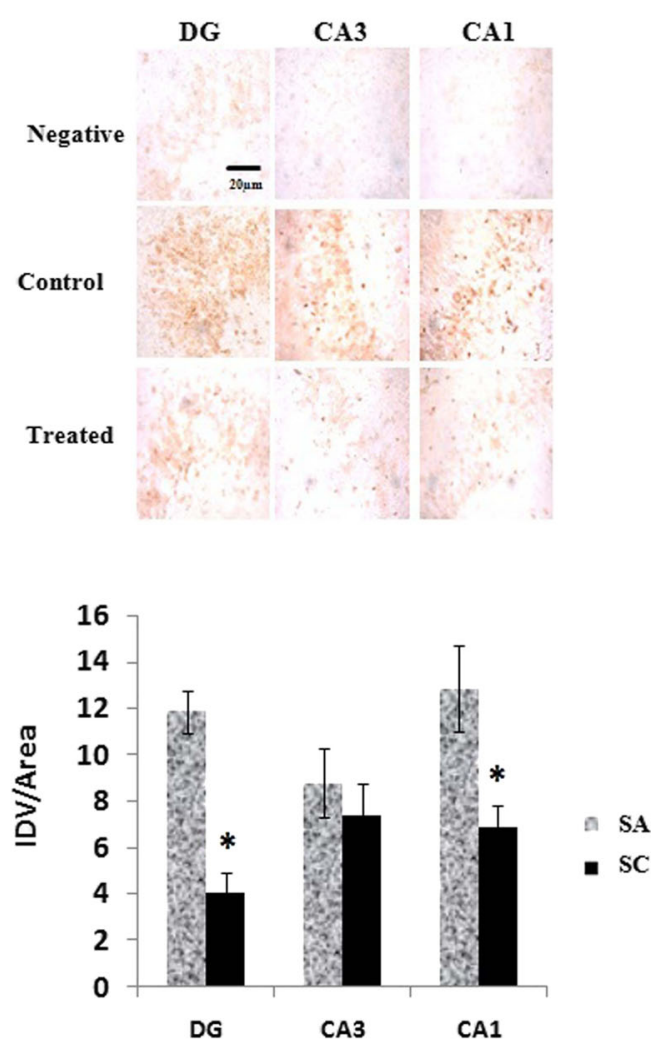

\section{Egr1}
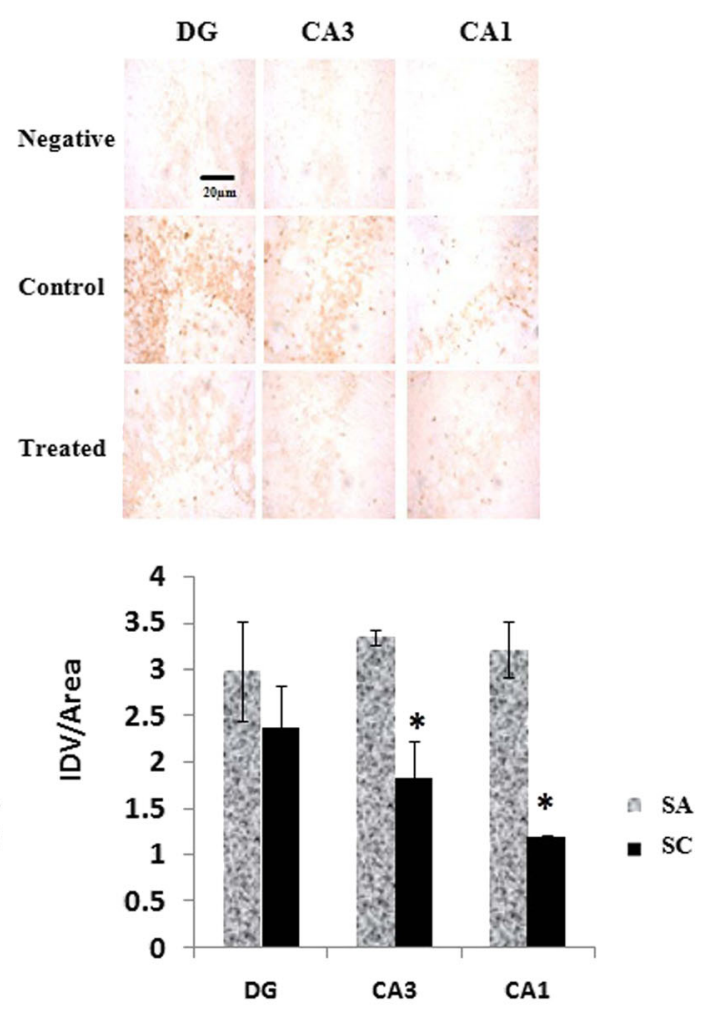

Narp
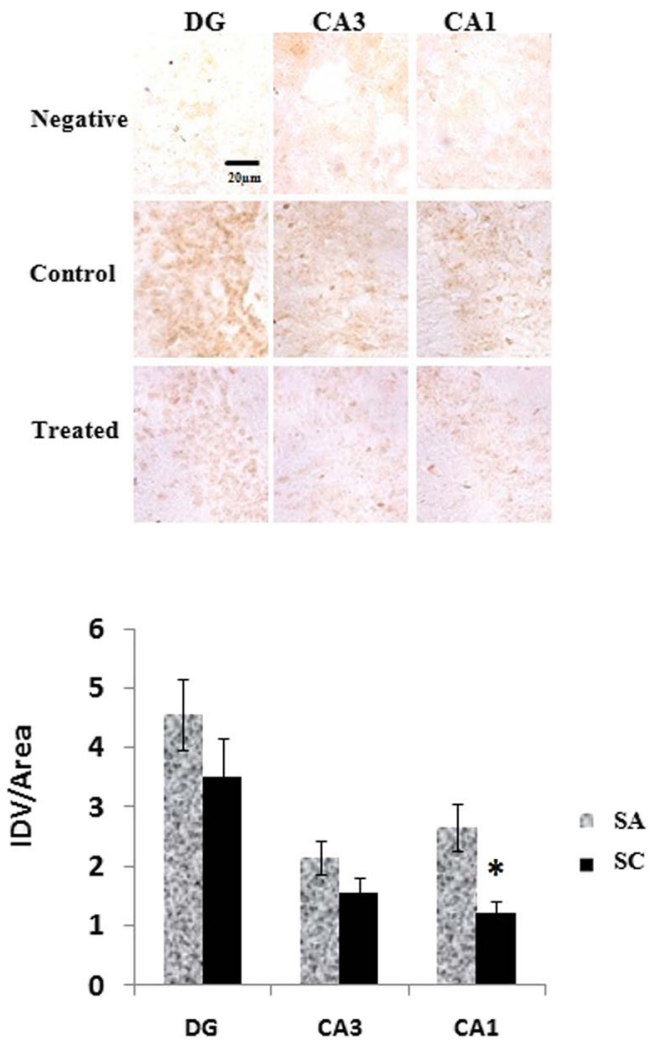
b
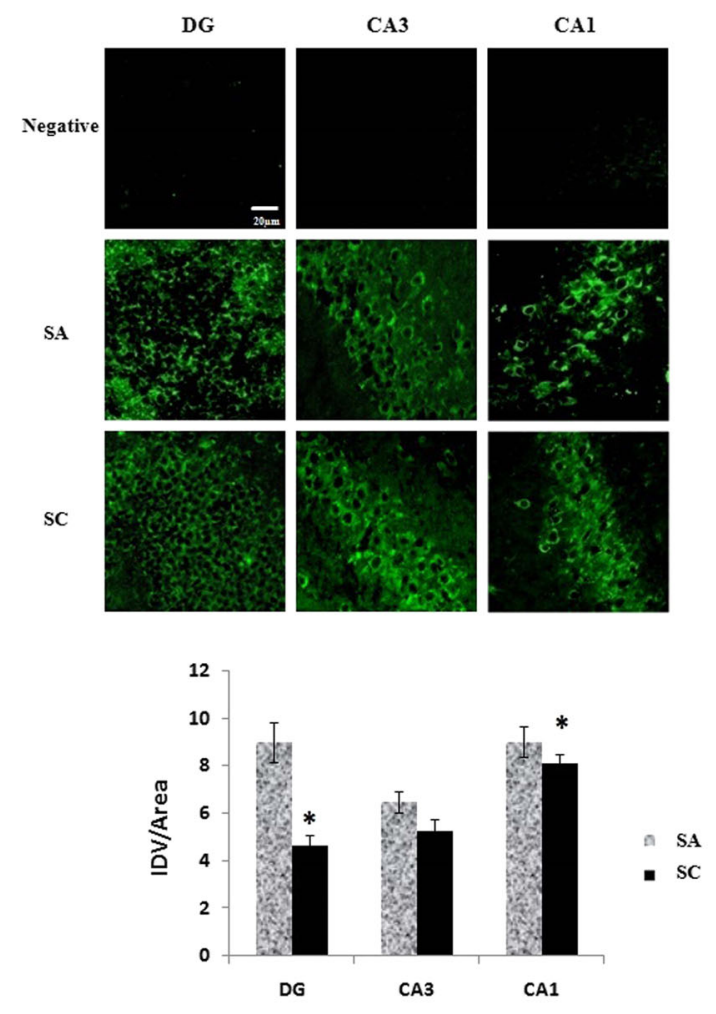

Homer1
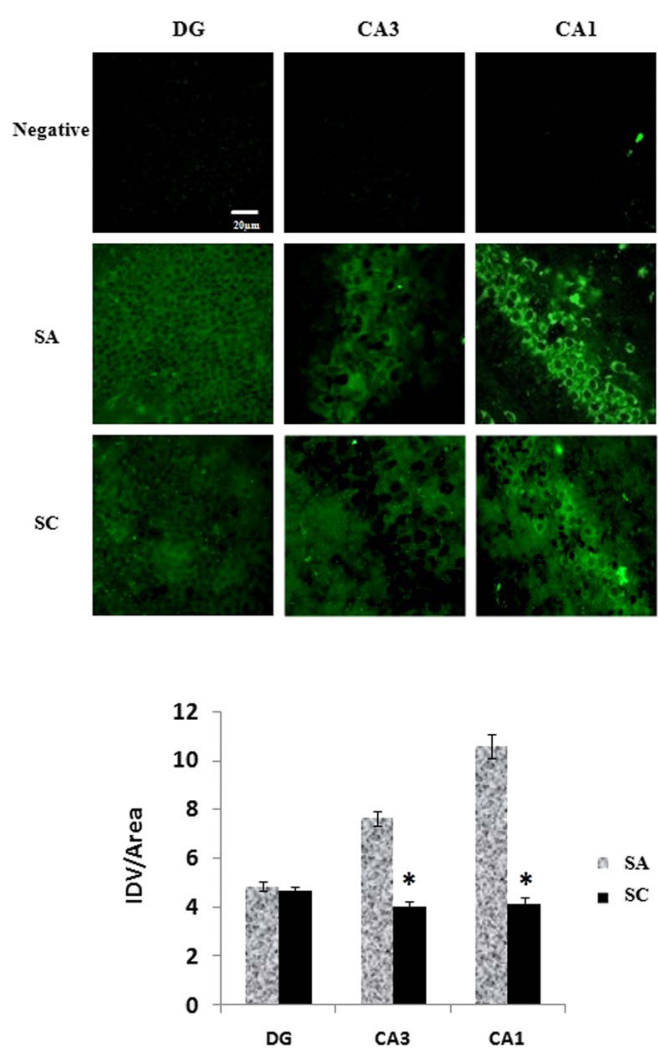

Fig. 3 continued.
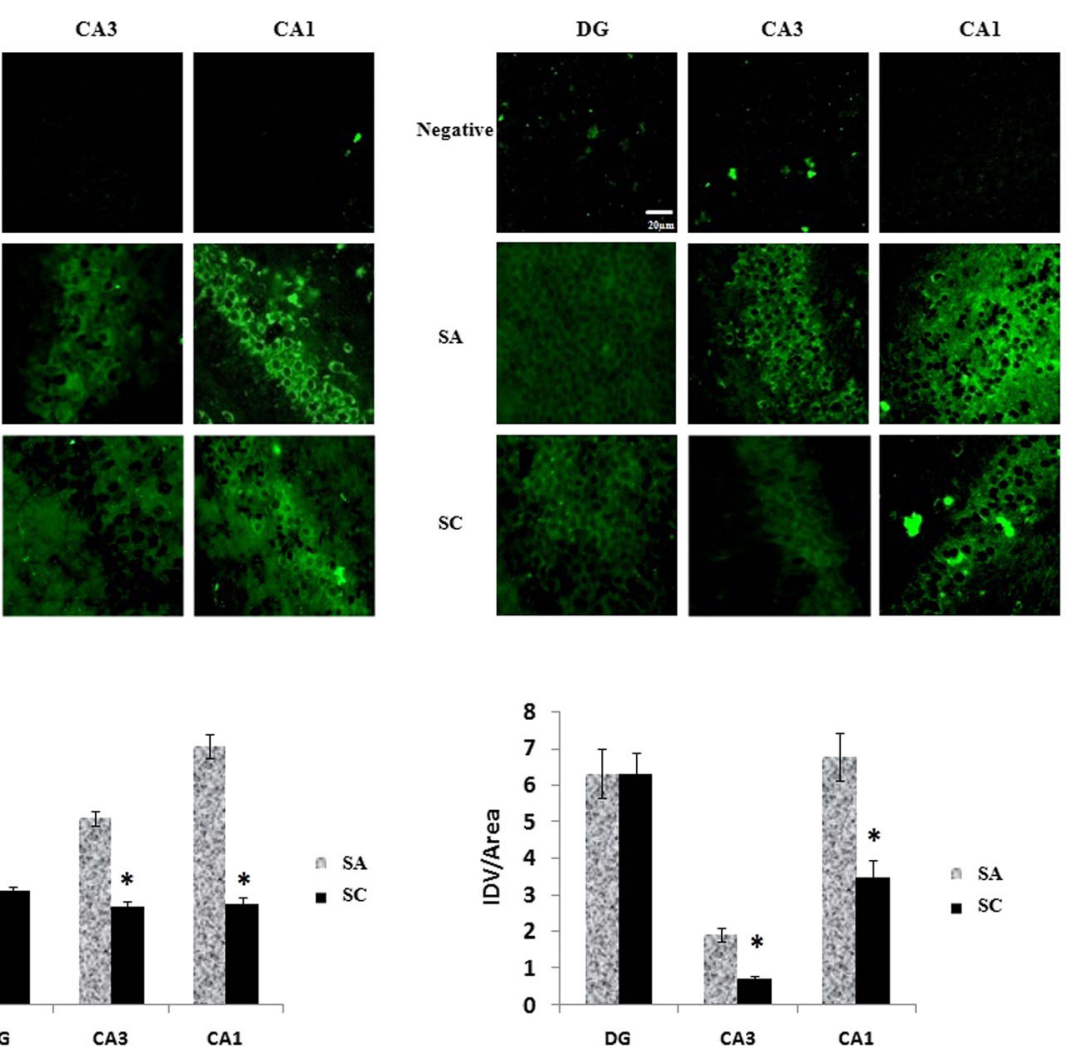
Publisher's Note Springer Nature remains neutral with regard to jurisdictional claims in published maps and institutional affiliations. 